\title{
Pharmacokinetics of Arctigenin and Fructus Arctii Powder in Piglets
}

\author{
Bin He ${ }^{1}$, Hai-Jing Zhang ${ }^{2}$, Wen-Hai Yang ${ }^{1}$, Zhi-Yong Shao ${ }^{1}$, Li-Jun $W^{1}{ }^{1}$, Xia-Bing Chen ${ }^{1}$, \\ Jie Chen ${ }^{1}$, Wu Liu ${ }^{1}$, Zhi-Ping Ran ${ }^{1}$, Rr-Guang Jin ${ }^{1}$ and Ji-Yue Cao ${ }^{3 *}$ \\ ${ }^{1}$ Institute of Animal Husbandry and Veterinary, Wuhan Academy of Agricultural Sciences, Wuhan, China, ${ }^{2}$ Tianjin Baodi \\ District Animal Husbandry and Aquaculture Development Service Center, Tianjin, China, ${ }^{3}$ College of Veterinary Medicine, \\ Huazhong Agricultural University, Wuhan, China
}

Fructus arctii, also known as great power seed, is the dried fruit of Arctium lappa of the family Compositae. It is a commonly used veterinary herbal medicine, and arctigenin is the main active ingredient. The aim of this study was to characterize the absorption, distribution, metabolism, and excretion of arctigenin and Fructus arctii powder in piglets. These data were used to provide a theoretical reference for the development and clinical use of new veterinary drugs. Sixteen healthy piglets (mean weight $30.0 \pm 5.0 \mathrm{~kg}$ ) were divided into two groups. One group was administered
OPEN ACCESS

Edited by:

Nora Mestorino,

National University of

La Plata, Argentina

Reviewed by:

Ankara University, Turkey Ender Yarsan

Ankara University, Turkey Arturo Anadón,

Complutense University of Madrid, Spain

*Correspondence: Ji-Yue Cao caojiyue@mail.hzau.edu.cn

Specialty section: This article was submitted to Veterinary Pharmacology and Toxicology,

a section of the journa

Frontiers in Veterinary Science

Received: 19 April 2019

Accepted: 02 July 2019

Published: 25 July 2019

Citation:

He B, Zhang H-J, Yang W-H, Shao Z-Y, Wu L-J, Chen X-B, Chen J, Liu W, Ran Z-P, Jin R-G and Cao J-Y (2019) Pharmacokinetics of Arctigenin and Fructus Arctii Powder in Piglets.

Front. Vet. Sci. 6:235 doi: 10.3389/fvets.2019.00235
Ayhan Filazi, $2.0 \mathrm{mg} / \mathrm{kg}$ body weight (bw) arctigenin intravenously, and the other was administered $1.0 \mathrm{~g} / \mathrm{kg} \cdot \mathrm{bw}$ Fructus arctii powder by gavage. Blood samples were collected from the anterior vena cava at different time points, and the concentration of arctigenin in the plasma of the piglets was determined using high-performance liquid chromatography (HPLC). Arctigenin conformed to a two-compartment model with no absorption, and the main pharmacokinetic parameters were as follows: distribution half-life $\left(t_{1 / 2 \alpha}\right)-0.166$ $\pm 0.022 \mathrm{~h}$; elimination half-life $\left(t_{1 / 2 \beta}\right)-3.161 \pm 0.296 \mathrm{~h}$; apparent volume of distribution $\left(V_{\mathrm{d}}\right)-0.231 \pm 0.033 \mathrm{~L} / \mathrm{kg}$; clearance rate $\left(\mathrm{CL}_{\mathrm{b}}\right)-0.057 \pm 0.003 \mathrm{~L} /(\mathrm{h} . \mathrm{kg})$; and area under the curve (AUC) $-1.189 \pm 0.057 \mathrm{~g} \cdot \mathrm{h} / \mathrm{mL}$. The pharmacokinetic parameters of arctigenin following oral administration of the Fructus arctii powder were as follows: absorption half-life $\left(t_{1 / 2 \mathrm{ka}}\right)-0.274 \pm 0.102 \mathrm{~h}, t_{1 / 2 \alpha}-1.435 \pm 0.725 \mathrm{~h}, t_{1 / 2 \beta}-63.467 \pm 29.115 \mathrm{~h}$, $V_{\mathrm{d}}-1.680 \pm 0.402 \mathrm{~L} / \mathrm{kg}, \mathrm{CL}_{b}-0.076 \pm 0.028 \mathrm{~L} /(\mathrm{h} \mathrm{kg})$, peak time $\left(t_{\max }\right)-0.853 \pm$ $0.211 \mathrm{~h}$, peak concentration $\left(C_{\max }\right)-0.430 \pm 0.035 \mathrm{~g} / \mathrm{mL}$, and $\mathrm{AUC}-14.672 \pm 4.813$ $\mathrm{g} / \mathrm{mL}$. These results indicated that intravenous arctigenin was sparingly distributed in tissues. In contrast, orally administered Fructus arctii powder was rapidly absorbed, more widely distributed, and more slowly eliminated than the intravenous arctigenin, which may indicate its sustained pharmacological effects.

Keywords: arctigenin, Fructus arctii powder, high-performance liquid chromatography, piglet, pharmacokinetics

\section{INTRODUCTION}

Fructus arctii, also known as great power seed, is the dried fruit of Arctium lappa of the family Compositae. It is a commonly used veterinary herbal medicine and is cold, pungent, and bitter in taste. It is associated with the lung and stomach meridians and can eliminate wind-heat and promote healing lung rashes. Arctium lappa is used by veterinarians to treat external wind-heat, cough, asthma, sore throat, and other conditions (1). The main active components 
of Fructus arctii are lignans, including arctiin and arctigenin (2). Arctiin can be converted, by gastrointestinal microorganisms, to arctigenin (3), which is the active component of Fructus arctii $(4,5)$. Arctigenin exerts anti-inflammatory $(5,6)$, antiviral $(7,8)$, antibacterial (9), antitumor $(10,11)$, and anti-diabetic (12) effects, and thus, it has excellent therapeutic potential. In this study, the pharmacokinetic characteristics of intravenously administered arctigenin and orally administered Fructus arctii powder in piglets were investigated to provide a theoretical basis and reference for the development and clinical use of arctigenin. Furthermore, this study will contribute to modernization of Chinese veterinary drugs.

\section{MATERIALS AND METHODS}

\section{Materials}

\section{Drugs}

Arctigenin standard (98.1\%; batch number, 160509) was purchased from Shanghai Ronghe Pharmaceutical Technology Co., Ltd. A standard solution containing $1.0 \mathrm{mg} / \mathrm{mL}$ arctigenin was prepared in a $5 \%$ methanol (aqueous) solution. An injection solution was prepared by dissolving arctigenin $(10.0 \mathrm{mg} / \mathrm{mL})$ in propylene glycol and water. Fructus arctii powder $(0.33 \%$ arctigenin and $4.33 \%$ arctiin) was prepared by crushing Fructus arctii to 100 mesh granules. Arctiin and arctigenin content in Fructus arctii powder was determined per the methods in the veterinary pharmacopeia of the People's Republic of China. The dosage of arctigenin and Fructus arctii powder in piglets was determined according to the veterinary pharmacopeia of the People's Republic of China.

\section{Instruments}

The instruments used in this study were an Agilent 1200 highperformance liquid chromatography (HPLC) system equipped with an autosampler and ultraviolet detector (USA), a D3024R high-speed centrifuge (Scilogex, USA), an electronic balance $(0.0001 \mathrm{~g})$ (Sedoris, Germany), and an N-EVAP ${ }^{\mathrm{TM}} 111$ Nitrogen Blowing Apparatus (Louis company, USA).

\section{Animals}

Sixteen healthy piglets (mean weight, $30.0 \pm 5.0 \mathrm{~kg}, 60$ days of age) were purchased from Wuhan Bomu Biotechnology Co., Ltd. They were randomly divided into two groups (nos. 1-8 and nos. 9-16). Each group consisted of four males (nos. 5-8 and 13-16) and four females (nos. 1-4 and 9-12). The piglets were housed in the animal experiment center of Wuhan Academy of Agricultural Sciences. The animal study was conducted per lab animal ethical review number 20160521031. The temperature of the pigsty was controlled at $\left(24.0 \pm 1.0^{\circ} \mathrm{C}\right)$, and the piglets were allowed free access to water and food. The feed was a diet without any drugs to prevent confounding results due to other drugs. Prior to execution of experiments, the piglets were fed normally for 2 weeks. After completion of the experiments, normal feeding was carried out.

\section{Method \\ Chromatographic Conditions}

The chromatographic column, detection wavelength, mobile phase, flow rate, injection volume, and column temperature were Agilent $\mathrm{SB}_{-} \mathrm{C}_{18}(250 \mathrm{~mm} \times 4.6 \mathrm{~mm}, 5 \mu \mathrm{m}), 280 \mathrm{~nm}$, methanol/acetonitrile/water $\quad(31: 20: 49 \mathrm{~V} / \mathrm{V} / \mathrm{V}), \quad 0.8 \mathrm{ml} / \mathrm{min}$, $30 \mu \mathrm{L}$, and $30 \pm 0.1^{\circ} \mathrm{C}$, respectively (13-15).

\section{Plasma Sample Treatment}

Plasma samples were stored in a $-20^{\circ} \mathrm{C}$ freezer and were thawed at $20 \pm 5^{\circ} \mathrm{C}$. Samples $(0.5 \mathrm{~mL})$ were accurately transferred to 5.0 $\mathrm{ml}$ centrifuge tubes, $2.0 \mathrm{~mL}$ of dichloromethane was added, and the mixture was vortexed for $60 \mathrm{~s}$. The mixture was centrifuged at $9,000 \times g$ for $10.0 \mathrm{~min}$ to separate the dichloromethane. The dichloromethane layers were extracted twice using this method and combined. The dichloromethane extracts were placed in

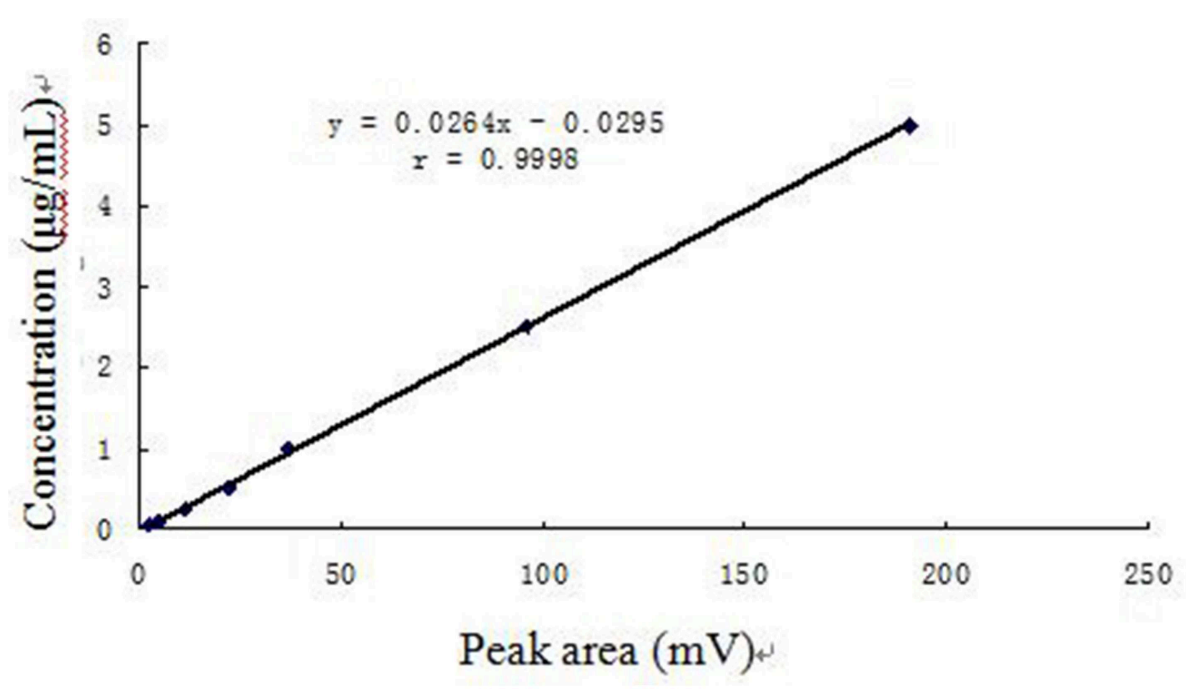

FIGURE 1 | Calibration curve of arctigenin in piglet plasma. 
15.0- $\mathrm{mL}$ centrifuge tubes and dried under nitrogen at $40^{\circ} \mathrm{C}$ in a water bath. The residue was dissolved in $200 \mu \mathrm{L}$ of mobile phase, centrifuged at $9,000 \times g$ for $10.0 \mathrm{~min}$, and the supernatant was filtered through a $0.22-\mu \mathrm{m}$ filter. The filtrate $(30 \mu \mathrm{L})$ was injected onto the HPLC system for analysis (16-18).

\section{Establishment of Plasma Standard Curve}

Blank plasma $(500 \mu \mathrm{L})$ was added to $5.0-\mathrm{mL}$ polypropylene centrifuge tubes, and this was followed by a series of diluted arctigenin working standard solutions. The resulting spiked plasma samples contained $0.05,0.1,0.25,0.5,1.0,2.5$, and $5.0 \mu \mathrm{g} / \mathrm{mL}$ arctigenin. The samples were extracted using the procedure described in section Plasma Sample Treatment and analyzed using HPLC. The measured peak area $(x)$ and concentration $(y)$ of arctigenin were plotted, and the standard curve in plasma was established. The regression equation was used to calculate the correlation coefficient $(r)$.

\section{Method Verification}

Blank plasma $(500 \mu \mathrm{L})$ was transferred to $5.0-\mathrm{mL}$ polypropylene centrifuge tubes. Diluted bovine aglycone working standard solutions at high, medium, or low concentrations were added, and the solutions were mixed well. The samples were prepared (5.0, 1.0, and $0.1 \mu \mathrm{g} / \mathrm{mL}$ ) according to the section Plasma Sample Treatment and analyzed using HPLC. Five concentrations were analyzed each day to determine the intraday coefficient of variation. Repeat analyses were evaluated on five different days to determine the interday coefficient of variation. Furthermore, the recovery, accuracy, precision, and sensitivity of the method were calculated according to the following formulae:

Accuracy (extraction recovery) $=$ peak area of drug injected after sample extraction/peak area after standard solution injection $\times 100 \%$;

Precision (intraday and interday coefficient of variation) $=$ standard deviation/average $\times 100 \%$;

Limit of detection (LOD): The lowest concentration at which the signal-to-noise ratio $(\mathrm{S} / \mathrm{N})$ was $\geq 3$;

Limit of quantification (LOQ): The minimum concentration at which $\mathrm{S} / \mathrm{N}$ was $\geq 10$, and the accuracy and precision were both within the acceptance criteria.

\section{Pharmacokinetic Test Design}

The pigs were fasted for $12.0 \mathrm{~h}$ prior to administration of arctigenin and Fructus arctii powder. Each piglet was weighed, and blood samples were collected from the anterior vena cava as blank controls. The first group of piglets (nos. 1-8) was administered $2.0 \mathrm{mg} / \mathrm{kg}$ body weight (bw) arctigenin by intravenous injection, and the second group (nos. 9-16) was given $1.0 \mathrm{~g} / \mathrm{kg} \cdot \mathrm{bw}$ Fructus arctii powder by gavage. In both groups, blood samples were collected from the anterior vena cava $(5.0 \mathrm{~mL})$ at $0.167,0.333,0.5,0.75,1.0,1.5,2.0,3.0,4.0,5.0,6.0$, and $8.0 \mathrm{~h}$ for the first group, and at additional time points of 12.0, 24.0, and $48.0 \mathrm{~h}$ for the second group (nos. 9-16 piglets). Blood samples were collected in heparinized polypropylene centrifuge tubes. The samples were centrifuged for $15.0 \mathrm{~min}$ at 3,000 $\times \mathrm{g}$, and the supernatants were collected and stored at $-20^{\circ} \mathrm{C}$ until pharmacokinetic analysis (19).

\section{Determination of Arctigenin Concentration in Piglet Plasma}

The plasma samples collected at each time point after arctigenin administration were analyzed by HPLC (according to the section Plasma Sample Treatment), the peak area of arctigenin was calculated, and the standard curve regression equation was used to calculate the plasma concentration of arctigenin.

\section{Data Analysis}

Excel software was used to generate the plasma standard curve and the concentration-time curve. Pharmacokinetic model fitting and pharmacokinetic parameters were analyzed using the 3p97 pharmacokinetic software created by a mathematical professional committee of the Chinese Pharmacological Society.

\section{EXPERIMENTAL RESULTS}

\section{Chromatographic Behavior of Arctigenin in Plasma}

The retention time of arctigenin (ACT) was $14.0 \mathrm{~min}$. The peak was symmetrical, the chromatogram showed a stable baseline, and the peak was well resolved from the impurity peak. The method also showed good sensitivity for arctigenin.

\section{Plasma Standard Curve}

The plasma concentration curve for arctigenin was linear $(r=0.9998)$ across the range of $0.05-10.0 \mu \mathrm{g} / \mathrm{mL}$. The regression equation was $y=0.0265 x-0.0328$ (where $x$ represents the peak area of arctigenin and $y$ represents the plasma concentration of arctigenin). The calibration curve of arctigenin in piglet plasma is shown in Figure 1.
TABLE 1 | Intraday recovery and precision values for the determination of arctigenin in piglet plasma $(n=5)$.

\begin{tabular}{lcc}
\hline $\begin{array}{l}\text { Arctigenin } \\
\text { concentration }(\mu \mathrm{g} / \mathrm{mL})\end{array}$ & $\begin{array}{c}\text { Recovery (\%) } \\
(\overline{\boldsymbol{x}} \pm \text { S.D) }\end{array}$ & $\begin{array}{c}\text { Coefficient of } \\
\text { intraday variation } \\
(\%)\end{array}$ \\
\hline 0.1 & $89.69 \pm 2.79$ & 3.11 \\
1 & $91.19 \pm 3.20$ & 3.51 \\
5 & $93.08 \pm 1.98$ & 2.13
\end{tabular}

TABLE 2 | Interday recovery and precision values for the determination of arctigenin in piglet plasma $(n=5)$.

\begin{tabular}{lcc}
\hline $\begin{array}{l}\text { Arctigenin } \\
\text { concentration }(\mu \mathrm{g} / \mathrm{mL})\end{array}$ & $\begin{array}{c}\text { Recovery (\%) } \\
(\overline{\boldsymbol{x}} \pm \text { S.D) }\end{array}$ & $\begin{array}{c}\text { Coefficient of } \\
\text { interday variation } \\
(\%)\end{array}$ \\
\hline 0.1 & $83.35 \pm 4.92$ & 5.90 \\
1 & $91.25 \pm 4.36$ & 4.77 \\
5 & $88.99 \pm 0.80$ & 0.90
\end{tabular}


TABLE 3 | Blood concentration of arctigenin in piglets after intravenous injection (2.0 mg/kg.bw).

\begin{tabular}{|c|c|c|c|c|c|c|c|c|c|}
\hline \multirow[t]{2}{*}{ Time (h) } & \multicolumn{8}{|c|}{ Blood concentration per piglet $(\mu \mathrm{g} / \mathrm{mL})$} & \multirow{2}{*}{$\begin{array}{l}\text { Average blood concentration } \\
\qquad(\bar{x} \pm \text { S.D. })\end{array}$} \\
\hline & 1 & 2 & 3 & 4 & 5 & 6 & 7 & 8 & \\
\hline 0.167 & 0.913 & 0.924 & 0.942 & 0.874 & 0.934 & 0.891 & 0.937 & 0.876 & $0.911 \pm 0.026$ \\
\hline 0.333 & 0.500 & 0.548 & 0.558 & 0.447 & 0.571 & 0.523 & 0.498 & 0.534 & $0.522 \pm 0.037$ \\
\hline 0.5 & 0.338 & 0.309 & 0.359 & 0.367 & 0.321 & 0.364 & 0.346 & 0.371 & $0.347 \pm 0.021$ \\
\hline 0.75 & 0.208 & 0.206 & 0.236 & 0.227 & 0.254 & 0.210 & 0.235 & 0.236 & $0.227 \pm 0.016$ \\
\hline 1.0 & 0.200 & 0.182 & 0.211 & 0.203 & 0.193 & 0.181 & 0.186 & 0.179 & $0.192 \pm 0.011$ \\
\hline 1.5 & 0.124 & 0.108 & 0.137 & 0.118 & 0.132 & 0.118 & 0.154 & 0.106 & $0.125 \pm 0.015$ \\
\hline 2.0 & 0.097 & 0.081 & 0.110 & 0.092 & 0.087 & 0.094 & 0.106 & 0.086 & $0.094 \pm 0.010$ \\
\hline 3.0 & 0.092 & 0.076 & 0.097 & 0.081 & 0.073 & 0.083 & 0.095 & 0.072 & $0.084 \pm 0.010$ \\
\hline 4.0 & 0.081 & 0.071 & 0.086 & 0.076 & 0.068 & 0.073 & 0.081 & 0.064 & $0.075 \pm 0.007$ \\
\hline 5.0 & 0.060 & 0.063 & 0.065 & 0.055 & 0.061 & 0.064 & 0.071 & 0.059 & $0.062 \pm 0.004$ \\
\hline 6.0 & 0.054 & 0.052 & 0.060 & 0.053 & 0.051 & 0.055 & 0.063 & 0.051 & $0.055 \pm 0.004$ \\
\hline 8.0 & ND & ND & ND & ND & ND & ND & ND & ND & ND \\
\hline
\end{tabular}

ND, not detected.

TABLE 4 | Pharmacokinetic parameters of arctigenin $(2.0 \mathrm{mg} / \mathrm{kg} \cdot \mathrm{bw})$ in piglets after intravenous injection.

\begin{tabular}{lcc}
\hline Pharmacokinetic parameter & Units & $(\bar{x} \pm$ S.D. $)$ \\
\hline$A$ & $\mu \mathrm{g} / \mathrm{mL}$ & $1.479 \pm 0.191$ \\
$\alpha$ & $\mathrm{h}^{-1}$ & $4.194 \pm 0.551$ \\
$B$ & $\mu \mathrm{g} / \mathrm{mL}$ & $0.187 \pm 0.023$ \\
$\beta$ & $\mathrm{h}^{-1}$ & $0.221 \pm 0.022$ \\
$V_{\mathrm{d}}$ & $\mathrm{L} / \mathrm{kg}$ & $0.307 \pm 0.033$ \\
$t_{1 / 2 \alpha}$ & $\mathrm{h}$ & $0.166 \pm 0.022$ \\
$t_{1 / 2 \beta}$ & $\mathrm{h}$ & $3.161 \pm 0.296$ \\
$\mathrm{~K}_{21}$ & $\mathrm{~h}^{-1}$ & $0.673 \pm 0.085$ \\
$\mathrm{~K}_{10}$ & $\mathrm{~h}^{-1}$ & $1.399 \pm 0.163$ \\
$\mathrm{~K}_{12}$ & $\mathrm{~h}^{-1}$ & $2.396 \pm 0.349$ \\
$\mathrm{~A} \cup \mathrm{C}$ & $\mu \mathrm{g} \cdot \mathrm{h} / \mathrm{mL}$ & $1.189 \pm 0.057$ \\
$\mathrm{CL} b$ & $\mathrm{~L} /(\mathrm{h} \cdot \mathrm{kg})$ & $0.068 \pm 0.003$ \\
\hline
\end{tabular}

\section{Method Verification}

The detection limit of arctigenin in piglet plasma was $0.025 \mu \mathrm{g} / \mathrm{mL}$, and the lower LOQ was $0.05 \mu \mathrm{g} / \mathrm{mL}$. The arctigenin response was linear across the range of $0.05-5.0 \mu \mathrm{g} / \mathrm{mL}$, the regression equation was $y=0.0264 x-0.0295$, and the correlation coefficient was 0.9998 . Recovery was $83.35 \%$ greater, the intraday variation was no more than $3.51 \%$, and the interday variation was no more than $5.90 \%$. Recovery, interday variation, and intraday variation are summarized in Tables 1, 2.

\section{Pharmacokinetic Test Data Intravenous Arctigenin Injection}

The blood arctigenin concentration time course in piglets after a single intravenous injection of arctigenin $(2.0 \mathrm{mg} / \mathrm{kg} . \mathrm{bw})$ is summarized in Table 3, the main pharmacokinetics parameters are summarized in Table $\mathbf{4}$, and the blood arctigenin concentration-time curve is shown in Figure 2.
After intravenous injection of arctigenin, the plasma concentration-time data of the arctigenin piglets conformed to the non-absorbed two-compartment model with the formula $C=1.479 \mathrm{e}^{-4.194 \mathrm{t}}+0.187 \mathrm{e}^{-0.221 \mathrm{t}}$. The distribution half-life $\left(t_{1 / 2 \alpha}\right)$ was $0.166 \pm 0.022 \mathrm{~h}$, the elimination half-life $\left(t_{1 / 2 \beta}\right)$ was $3.161 \pm 0.296 \mathrm{~h}$, and the apparent volume of distribution $\left(V_{\mathrm{d}}\right)$ was $0.231 \pm 0.033 \mathrm{~L} / \mathrm{kg}$. These results suggested that, in piglets, burdock glycosides were distributed rapidly, but distribution into tissues was low and elimination was rapid due to metabolism.

\section{Oral Administration (by Gavage) of Fructus Arctii Powder}

The time course of blood arctigenin concentration in piglets fed a single dose of Fructus arctii powder $(1.0 \mathrm{~g} / \mathrm{kg} \cdot \mathrm{bw})$ is shown in Table 5, the main pharmacokinetic parameters are shown in Table 6, and the blood arctigenin concentration-time curve is shown in Figure 3.

The blood arctigenin concentration-time data adhered to the absorption chamber model. The formula was $C=0.644 \mathrm{e}^{-0.567 \mathrm{t}}$ $+0.160 \mathrm{e}^{-0.013 \mathrm{t}}-0.864 \mathrm{e}^{-1.826 \mathrm{t}}$, the curve was bimodal, $t_{\max }$ was $0.853 \pm 0.211 \mathrm{~h}$, the maximum concentration $\left(C_{\max }\right)$ was $0.430 \pm$ $0.035 \mu \mathrm{g} / \mathrm{mL}$, the absorption half-life $\left(t_{1 / 2 \mathrm{ka}}\right)$ was $0.274 \pm 0.102 \mathrm{~h}$, the elimination half-life $\left(t_{1 / 2 \beta}\right)$ was $63.467 \pm 29.115 \mathrm{~h}$, and the apparent volume of distribution $\left(V_{\mathrm{d}}\right)$ was $1.680 \pm 0.402 \mathrm{~L} / \mathrm{kg}$. The powder was rapidly absorbed, widely distributed, and was slowly eliminated.

\section{DISCUSSION}

Arctigenin has excellent therapeutic potential. This study evaluated the pharmacokinetics of arctigenin and Fructus arctii to characterize their absorption, distribution, metabolism, and excretion in piglets and provides a theoretical basis and reference for the development and clinical use of new veterinary drugs.

After intravenous injection of arctigenin, the distribution half-life $\left(t_{1 / 2 \alpha}\right)(0.166 \pm 0.022 \mathrm{~h})$ was short and the apparent 


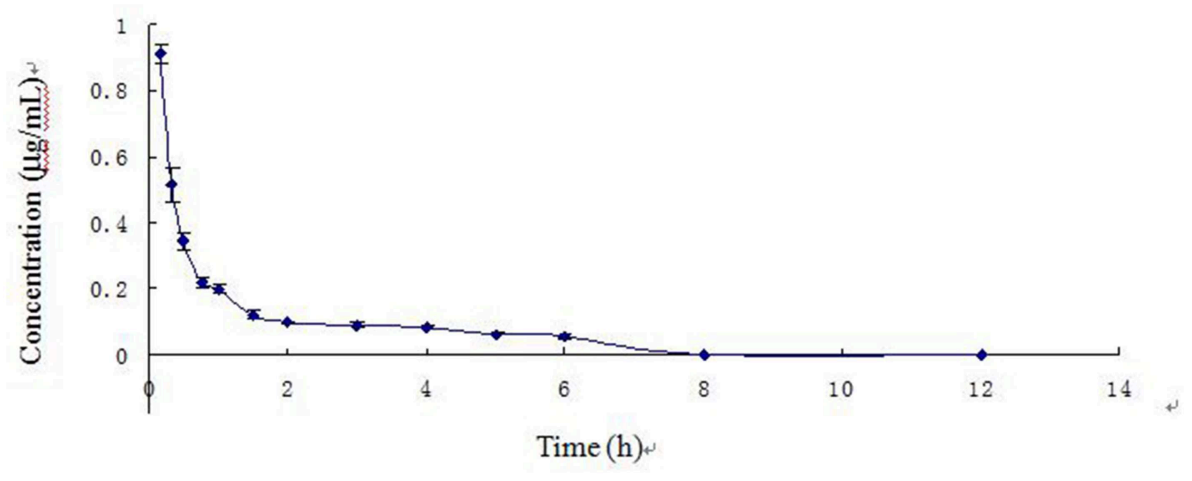

FIGURE 2 | Blood concentration-time curve of arctigenin in piglets after intravenous injection $(2.0$ mg/kg).

TABLE 5 | Blood concentration ( $\mu \mathrm{g} / \mathrm{mL})$ of arctigenin in piglets after a single oral dose of Fructus arctii powder (1.0 g/kg.bw).

\begin{tabular}{|c|c|c|c|c|c|c|c|c|c|}
\hline \multirow[t]{2}{*}{ Time (h) } & \multicolumn{8}{|c|}{ Blood concentration per piglet $(\mu \mathrm{g} / \mathrm{mL})$} & \multirow{2}{*}{$\begin{array}{l}\text { Average blood concentration } \\
\qquad(\bar{x} \pm \text { S.D. })\end{array}$} \\
\hline & 9 & 10 & 11 & 12 & 13 & 14 & 15 & 16 & \\
\hline 0.167 & 0.179 & 0.187 & 0.161 & 0.216 & 0.242 & 0.195 & 0.166 & 0.250 & $0.200 \pm 0.031$ \\
\hline 0.333 & 0.258 & 0.271 & 0.242 & 0.274 & 0.306 & 0.216 & 0.211 & 0.282 & $0.258 \pm 0.031$ \\
\hline 0.5 & 0.594 & 0.572 & 0.633 & 0.665 & 0.625 & 0.549 & 0.609 & 0.601 & $0.606 \pm 0.034$ \\
\hline 0.75 & 0.279 & 0.250 & 0.295 & 0.240 & 0.285 & 0.322 & 0.290 & 0.256 & $0.277 \pm 0.025$ \\
\hline 1.0 & 0.401 & 0.285 & 0.359 & 0.335 & 0.306 & 0.369 & 0.335 & 0.390 & $0.348 \pm 0.037$ \\
\hline 1.5 & 0.454 & 0.385 & 0.382 & 0.398 & 0.364 & 0.422 & 0.459 & 0.440 & $0.413 \pm 0.034$ \\
\hline 2.0 & 0.433 & 0.369 & 0.337 & 0.385 & 0.343 & 0.401 & 0.396 & 0.417 & $0.385 \pm 0.032$ \\
\hline 3.0 & 0.213 & 0.242 & 0.258 & 0.205 & 0.242 & 0.279 & 0.301 & 0.237 & $0.247 \pm 0.030$ \\
\hline 4.0 & 0.195 & 0.211 & 0.240 & 0.192 & 0.229 & 0.258 & 0.200 & 0.227 & $0.219 \pm 0.022$ \\
\hline 5.0 & 0.176 & 0.187 & 0.216 & 0.179 & 0.163 & 0.229 & 0.195 & 0.203 & $0.194 \pm 0.020$ \\
\hline 6.0 & 0.147 & 0.169 & 0.203 & 0.158 & 0.161 & 0.198 & 0.161 & 0.192 & $0.174 \pm 0.020$ \\
\hline 8.0 & 0.145 & 0.139 & 0.126 & 0.134 & 0.108 & 0.187 & 0.158 & 0.153 & $0.144 \pm 0.022$ \\
\hline 12.0 & 0.132 & 0.121 & 0.124 & 0.100 & 0.103 & 0.184 & 0.142 & 0.132 & $0.130 \pm 0.025$ \\
\hline 24.0 & 0.105 & 0.095 & 0.100 & 0.089 & 0.079 & 0.142 & 0.124 & 0.126 & $0.108 \pm 0.020$ \\
\hline 48.0 & 0.100 & 0.071 & 0.095 & 0.066 & 0.077 & 0.121 & 0.079 & 0.105 & $0.089 \pm 0.018$ \\
\hline
\end{tabular}

distribution volume $\left(V_{\mathrm{d}}\right)(0.307 \pm 0.033 \mathrm{~L} / \mathrm{kg})$ was low, indicating that arctigenin was rapidly distributed, but distribution into tissues was relatively low. Arctigenin was mainly distributed in the blood and the extracellular fluid (19). The elimination half-life $\left(t_{1 / 2 \beta}\right)(3.161 \pm 0.296 \mathrm{~h})$ was relatively short, indicating that elimination occurred rapidly and did not correlate with distribution.

The absorption half-life $\left(t_{1 / 2 \mathrm{ka}}\right)$ of Fructus arctii powder was $0.274 \pm 0.102 \mathrm{~h}$ and the peak time $\left(t_{\max }\right)$ was $0.853 \pm 0.211 \mathrm{~h}$, indicating that absorption was rapid and the time to reach the maximum blood concentration was short. The $t_{1 / 2 \beta}(63.467 \pm$ $29.115 \mathrm{~h})$ was long, the $V_{\mathrm{d}}(1.680 \pm 0.402 \mathrm{~L} / \mathrm{k})$ was large, and the peak concentration $C_{\max }(0.430 \pm 0.035 \mu \mathrm{g} / \mathrm{mL})$ was relatively low. These results indicate that arctigenin was eliminated slowly and was distributed to tissues, resulting in a relatively low concentration of the drug in the blood, which may indicate a sustained pharmacological effect (17). A previous report showed that arctigenin was rapidly absorbed in rats and beagle dogs (absorption rate $<1 \mathrm{~h}$ ), showed a high degree of absorption (absolute bioavailability $>100 \%$ ), and was rapidly eliminated. The time course of tissue distribution of arctigenin in rats after intravenous administration was indicative of rapid $(2.5 \mathrm{~h}$ to reach the peak concentration) and wide (detectable in almost all tissues and organs) distribution. The arctigenin concentration was highest in the intestine, followed by that in the heart, liver, pancreas, and kidney (20). This was similar to the rapid and wide distribution we observed following oral administration of Fructus arctii to piglets. Comparison of pharmacokinetic parameters of arctigenin and Fructus arctii, it was found that the main differences in pharmacokinetic parameters were elimination half-life $\left(t_{1 / 2 \beta}\right)$, apparent volume of distribution $\left(V_{\mathrm{d}}\right)$, and area under the concentration-time curve (AUC). These differences were significant $(p<0.01)$. These results indicated that the gastrointestinal system greatly influenced 
the absorption, distribution, metabolism, and excretion of arctigenin.

After intravenous injection of arctigenin, the plasma concentration-time data in piglets conformed to the nonabsorbed two-compartment model. These results were similar to those of a previous study, which evaluated intravenous injection of different doses of arctigenin and its valine ester derivative in Wistar rats (21). The blood drug concentration-time curve was consistent with the two-compartment model. After oral administration of Fructus arctii, the blood concentration-time data of arctigenin in piglets were consistent with the twocompartment model of absorption. This is not in line with the characteristics of the one-compartment model after Wistar rats were orally administered different doses of arctiin and its valine ester derivative, which was reported by Cai et al. (21). These differences may have been species specific. The blood arctigenin

TABLE 6 | The main pharmacokinetic parameters in piglets after a single oral dose of Fructus arctii powder $(1.0 \mathrm{~g} / \mathrm{kg} \cdot \mathrm{bw})$.

\begin{tabular}{lcc}
\hline Pharmacokinetic parameter & Unit & $(\overline{\boldsymbol{x}} \pm$ S.D. $)$ \\
\hline$A$ & $\mu \mathrm{g} / \mathrm{mL}$ & $0.644 \pm 0.242$ \\
$\alpha$ & $\mathrm{h}^{-1}$ & $0.567 \pm 0.213$ \\
$B$ & $\mu \mathrm{g} / \mathrm{mL}$ & $0.160 \pm 0.036$ \\
$\beta$ & $\mathrm{h}^{-1}$ & $0.013 \pm 0.005$ \\
$K_{\alpha}$ & $\mathrm{h}^{-1}$ & $3.400 \pm 2.881$ \\
$V_{\mathrm{d}}$ & $\mathrm{L} / \mathrm{kg}$ & $1.680 \pm 0.402$ \\
$t_{1 / 2 \alpha}$ & $\mathrm{h}$ & $1.435 \pm 0.725$ \\
$t_{1 / 2 \beta}$ & $\mathrm{h}$ & $63.467 \pm 29.115$ \\
$t_{1 / 2 \mathrm{ka}}$ & $\mathrm{h}$ & $0.274 \pm 0.102$ \\
$\mathrm{~K}_{21}$ & $\mathrm{~h}^{-1}$ & $0.155 \pm 0.060$ \\
$\mathrm{~K}_{10}$ & $\mathrm{~h}^{-1}$ & $0.047 \pm 0.023$ \\
$\mathrm{~K}_{12}$ & $\mathrm{~h}^{-1}$ & $0.378 \pm 0.149$ \\
$\mathrm{AUC}$ & $\mu \mathrm{g} \cdot \mathrm{h} / \mathrm{mL}$ & $14.672 \pm 4.813$ \\
$\mathrm{CL}_{\mathrm{b}}$ & $\mathrm{L} /(\mathrm{h} \cdot \mathrm{kg})$ & $0.076 \pm 0.028$ \\
$t_{\mathrm{max}}$ & $\mathrm{h}$ & $0.853 \pm 0.211$ \\
$C_{\max }$ & $\mu \mathrm{g} / \mathrm{mL}$ & $0.430 \pm 0.035$ \\
& &
\end{tabular}

concentration-time curve of Fructus arctii powder was bimodal. The peak times $\left(T_{\max }\right)$ of the first and second curves were 0.5 and $1.5 \mathrm{~h}$, at which the peak concentrations $\left(C_{\max }\right)$ were 0.606 \pm 0.036 and $0.413 \pm 0.036 \mu \mathrm{g} / \mathrm{ml}$, respectively. This bimodal phenomenon was also observed in a pharmacodynamic study of Fructus arctii in mice by Yuan (22). Additionally, the author found that there were two peak concentrations, which indicated that the absorption process of the drug was unique and that the pharmacodynamics were related to the pharmacokinetics. The authors suggested that the two peaks might have resulted from the conversion of arctiin in the aqueous extract to arctigenin or the enterohepatic circulation of arctigenin. Gao et al. reported that arctigenin undergoes extensive glucuronic acid hydrolysis in the liver, intestine, and plasma, which may be associated with the dual absorption peaks of the drug, further suggesting that the drug remains in the body for a prolonged period (23). Ikeda et al. reported that the pharmacokinetics of arctigenin in the human body followed a non-linear model. This study observed a second absorption peak for arctiin and arctigenin, suggesting intrahepatic circulation (24). Gao et al. showed that glucaldehyde acidification is the main intestinal and liver metabolic pathway for arctigenin, and arctigenin excreted in the bile can be further hydrolyzed to arctiin, indicating potential enterohepatic circulation (25). Gao et al. found that hydrolysis was the main metabolic pathway of arctigenin; subsequently, arctigenic acid, arctigenin 4-O-glucuronide, and 4-O-demethylarctigenin were identified as three novel metabolites (26). These reports were similar to those indicating double absorption peaks of arctigenin in piglets following oral administration of Fructus arctii, which provided further support for hepatic and intestinal circulation of arctigenin in piglets.

Zeng et al. found that the function of p-glycoprotein was impaired in diabetic rats and that arctigenin is a substrate for p-glycoprotein, resulting in increases of 356.8 and $223.4 \%$ in the $C_{\max }$ and $\mathrm{AUC}_{0-10 \mathrm{~h}}$ values of arctigenin administered orally to diabetic rats compared with normal rats, respectively. However, after intravenous injection, there were no significant differences in $C_{\max }$ or $\mathrm{AUC}_{0-10 \mathrm{~h}}$ between normal and diabetic rats (27). The blood drug concentrations observed in the previous experiment by Zeng et al. and the present study were not

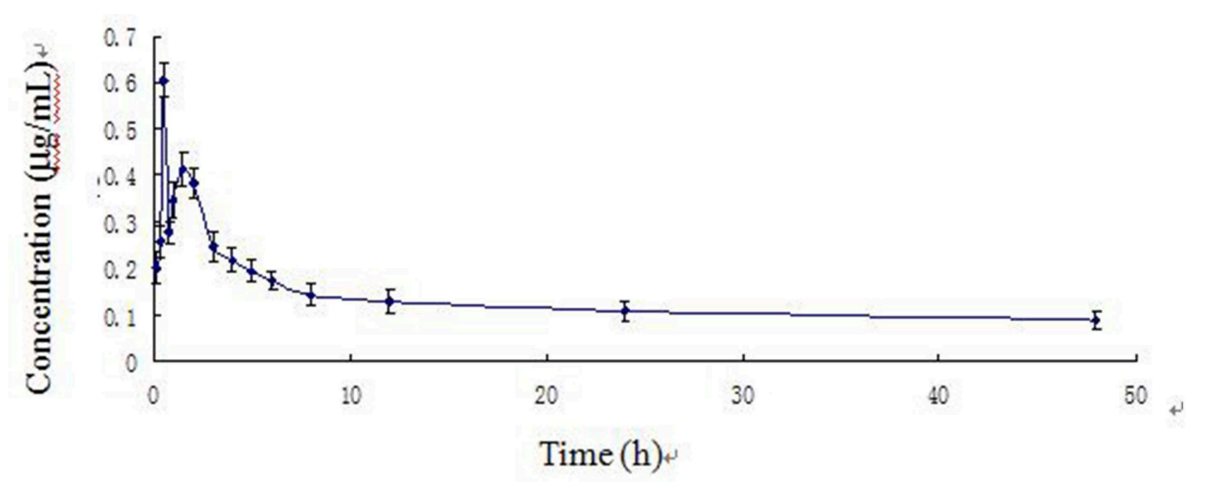

FIGURE 3 | Arctigenin concentration-time curve in piglets after a single oral dose of Fructus arctii powder (1.0 g/kg ·bw). 
affected by the physiological state of the piglets or the gender of the piglets. Furthermore, no significant differences were observed in the pharmacokinetic parameters between the two studies; presumably, the pharmacology and pharmacokinetics of arctigenin after oral or intravenous administration are not affected by physiological conditions, whether pathological or normal. However, the reality needs further investigation.

Pharmacokinetic studies of traditional Chinese medicines often result in bimodal absorption time courses due to the complex nature of these medicines and conversion of components to the same parent molecule (28). In a study by Guo et al. on the pharmacokinetics of orally administered baicalin and Radix Scutellariae in rats, the blood drug concentrationtime curve was bimodal. This may have been due to the hydrolysis of baicalin to its glycoside form by intestinal flora, resulting in enterohepatic circulation (29). Furthermore, this phenomenon may be associated with mother nuclear components sharing metabolic mechanisms (30). Yang et al. studied the pharmacokinetic characteristics of cinnamic acid in baoxin pellets in rats and found that the blood drug concentration-time curve was bimodal. Cinnamic aldehyde can be oxidized to cinnamic acid in vivo, and reabsorption resulted in a second absorption peak, which may have been indicative of enterohepatic circulation (31). The bimodal phenomenon observed in this study was likely caused by metabolism of arctiin to arctigenin. It is possible that the second peak resulted from enterohepatic circulation or through conversion of arctiin to arctigenin. The specific mechanism responsible for the bimodal absorption distribution of arctigenin should be investigated in future studies.

\section{CONCLUSION}

In this study, HPLC was used to quantitate arctigenin in piglet plasma. The method was sensitive, specific, and rapid. This method can be used to support preclinical pharmacokinetic studies of arctigenin with new veterinary drugs. The pharmacokinetic characteristics of Fructus arctii and its

\section{REFERENCES}

1. Gao HB, Yu KZ, Zhang ZQ, Fong ZW, Xu XJ, Xia XZ, et al. Commission of Chinese veterinary pharmacopoeia. In: People's Republic of China Veterinary Pharmacopoeia. Beijing: China Agriculture Press (2015). p. 101-2.

2. Ju MJ. Study on extraction technology of lignans from Arctium lappa $L$ (dissertation/doctoral thesis). Liaoning University of Traditional Chinese Medicine, ShenYang, China (2008).

3. Yu H. The chemical composition and biological activity of burdock. World Phytomed. (2007) 6:246-7.

4. Qi YM. Study on the chemical constituents of burdock (dissertation/doctoral thesis). Qiqihar University, Qiqihar, China (2012).

5. Cho MK, Jang YP, Kim YC, Kim SG. Arctigenin, a phenylpropanoid dibenzylbutyrolactone lignan, inhibits MAP kinases and AP-1 activation via potent MKK inhibition: the role in TNF-a inhibition. Int Immunopharmacol. (2004) 10:1419-29. doi: 10.1016/j.intimp.2004.06.011

6. Huang SH, Huang LD, Liu SL, Guo LQ, Wen QT, Xiao LB, et al. An experimental study of the analgesic and ant-inflammatory effects of extracts of Great Burdock Achene on mice. J Youjiang Med Univ National. (2012) 1:7-9. main active ingredient arctigenin in piglets were characterized. The results showed that intravenous administration of arctigenin exhibited a two-compartment model without absorption in piglets and showed poor tissue distribution, short half-life, and rapid elimination. Oral administration of Fructus arctii exhibited a two-compartment model of arctigenin absorption characterized by fast absorption, wide distribution, and slow elimination, with potential hepatoenteric circulation, which suggested that arctigenin may exert effects for a prolonged period of time. Dosing amount and frequency should be controlled to prevent side effects caused by drug accumulation in the body due to slow elimination.

\section{DATA AVAILABILITY}

All datasets generated for this study are included in the manuscript and/or the supplementary files.

\section{ETHICS STATEMENT}

There is no violation of ethics or animal welfare in this study. The experiment is authorized by Wuhan academy of agricultural sciences and is willing to accept social supervision.

\section{AUTHOR CONTRIBUTIONS}

All authors listed have made a substantial, direct and intellectual contribution to the work, and approved it for publication.

\section{FUNDING}

Hubei Provincial Natural Science Foundation of China: Regulatory mechanism of ACT on MyD88/NF- $\kappa$ B inflammatory signaling pathway activated by PCV2 infection, 2018CFB678. Wuhan Science and Technology Bureau platform project: Wuhan Animal and Poultry Chinese Herbal Medicine Development Engineering Technology Research Center, 2014021511020460.

7. Chen J, Li W, Jin E, He Q, Yan W, Yang H. The antiviral activity of arctigenin in traditional Chinese medicine on porcine circovirus type 2. Res Vet Sci. (2016) 6:159-64. doi: 10.1016/j.rvsc.2015. 10.012

8. Wang J. Study on antiviral effective parts of Arctium lappa. (dissertation/doctoral thesis). Liaoning College of Traditional Chinese Medicine, Shenyang, China (2004).

9. Liu K. In vitro antibacterial experiment of Fructus Arctium lappa decoction, Arctium aglycone and Arctium aglycone. Tianjin Pharm. (2008) 4:10-11.

10. Zhang XD, Zhang CQ, Liu QD, Li P, Qin KM, Cai BC. Research progress on antitumor constituents and mechanism of Arctium lappa L. Mod Chin Med. (2012) 12:12-5.

11. Liu KL. Studies on the chemical constituents of Arctium lappa L. and their antitumor effects (dissertation/master's thesis). Traditional Chinese Medicine University of Guangzhou, Guangzhou, China (2008).

12. Lu CL. Study on the separation and purification way of arctiin and study on the protective mechanism vascular endothelial cell of experimental diabetic rats with arctiin (dissertation/doctoral thesis). Army Medical University, Chongqing, China (2007). 
13. Kim CY, Ahn MJ, Kim J. A preparative isolation and purification of arctigenin and matairesinol from Forsythia koreana by centrifugal partition chromatography. J Sep Sci. (2006) 29:656-9. doi: 10.1002/jssc.200500316

14. Lv, J. Study on pharmacokinetics of arctigenin (dissertation/master's thesis). Liaoning College of Traditional Chinese Medicine, Shenyang, China (2002).

15. Ge L, Zhang HK, Tian SG. Content determination of arctiin and arctigen from different parts of Arctium tomentosum. by RP-HPLC. Chin J Exp Tradit Med Formulae. (2010) 14:41-43.

16. He F, Dou DQ, Sun Y, Zhu L, Xiao HB, Kang TG. Plasma pharmacokinetics and tissue distribution of arctiin and its main metabolite in rats by HPLC-UV and LC-MS. Planta Med. (2012) 8:800-6. doi: 10.1055/s-0031-1298433

17. He F, Dou DQ, Hou Q, Sun Y, Kang TG. Pharmacokinetic study of arctigenin in rat plasma and organ tissue by RP-HPLC method. Nat Prod Res. (2013) 10:903-6. doi: 10.1080/14786419.2012.666745

18. Jiang YX, Tian HC, Zhang JY, Han F. Pharmacokinetics of arctigenin nanoemulsion in rats. J Chin Pharm Sci. (2014) 8:679-68. doi: $10.11669 /$ cpj.2014.08.014

19. Cao JY, Lu XC. Veterinary Pharmacokinetics. Beijing: China Agricultural Press (2005).

20. Li J, Li X, Ren YS, Lv YY, Zhang JS, Xu XL, et al. Elucidation of arctigenin pharmacokinetics and tissue distribution after intravenous, oral, hypodermic and sublingual administration in rats and beagle dogs: integration of in vitro and in vivo findings. Front Pharmacol. (2017) 8:376. doi: 10.3389/fphar.2017.00376

21. Cai E, Song X, Han M, Yang L, Zhao Y, Li W, et al. Experimental study of the anti-tumour activity and pharmacokinetics of arctigenin and its valine ester derivative. Sci Rep. (2018) 8:3307. doi: 10.1038/s41598-018-21722-1

22. Yuan Y. Quality control method of burdock and its pharmacokinetics and pharmacodynamics of water extracts (dissertation/doctoral thesis). Liaoning University of Traditional Chinese Medicine, Shenyang, China (2009).

23. Gao Q, Yang M, Zuo Z. Overview of the anti-inflammatory effects, pharmacokinetic properties and clinical efficacies of arctigenin and arctiin from Arctium lappa L. Acta Pharmacol Sin. (2018) 39:787-801. doi: 10.1038/aps.2018.32

24. Ikeda M, Sato A, Mochizuki N, Toyosaki K, Miyoshi C, Fujioka R, et al. Phase I trial of GBS-01 for advanced pancreatic cancer refractory to gemcitabine. Cancer Sci. (2016) 107:1818-24. doi: 10.1111/cas.13086
25. Gao Q, Zhang Y, Wo S, Zuo Z. Elucidation of arctigenin pharmacokinetics after intravenous and oral administrations in rats: integration of in vitro and in vivo findings via semi-mechanistic pharmacokinetic modeling. AAPS J. (2014) 16:1321-33. doi: 10.1208/s12248-0149664-x

26. Gao Q, Zhang Y, Wo S, Zuo Z. Hydrolysis is the dominating in vivo metabolism pathway for arctigenin: identification of novel metabolites of arctigenin by LC/MS/MS after oral administration in rats. Planta Med. (2013) 79:471-9. doi: 10.1055/s-0032-1328332

27. Zeng XY, Dong S, He NN, Jiang CJ, Dai Y, Xia YF. Comparative pharmacokinetics of arctigenin in normal and type 2 diabetic rats after oral and intravenous administration. Fitoterapia. (2015) 105:119-26. doi: 10.1016/j.fitote.2015.06.014

28. Wei FH, Wang YG, Luo JB. Survey of research on multi-peak phenomenon of pharmacokinetics. Chin Pharm J. (2005) 23:1772-4.

29. Guo XY, Yang L, Chen Y, Che QM. Comparison of pharmacokinetics of baicalin and baicalein in rats. In: Proceedings of the 6th China Pharmaceutical Association Annual Conference. Guang Zhou (2009). p. 1203-9.

30. Shi R, Zhou H, Liu Z, Ma Y, Wang T, Liu Y, et al. Influence of Coptis chinensis on pharmacokinetics of flavonoids after oral administration of Radix Scutellariae in rats. Biopharm Drug Dispos. (2009) 7:398-410. doi: 10.1002/bdd.674

31. Yang CM, Hou SX, Sun YY, Li CY. Pharmacokinetics of cinnamic acid in Baoxin Pill in rat. Chin Tradit Herb Drugs. (2001) 7:616-8.

Conflict of Interest Statement: The authors declare that the research was conducted in the absence of any commercial or financial relationships that could be construed as a potential conflict of interest.

Copyright (c) 2019 He, Zhang, Yang, Shao, Wu, Chen, Chen, Liu, Ran, Jin and Cao. This is an open-access article distributed under the terms of the Creative Commons Attribution License (CC BY). The use, distribution or reproduction in other forums is permitted, provided the original author(s) and the copyright owner(s) are credited and that the original publication in this journal is cited, in accordance with accepted academic practice. No use, distribution or reproduction is permitted which does not comply with these terms. 